\title{
REQUISITOS DE PROJETO PARA DESIGN DE AMBIENTES VOLTADOS AO IDOSO COM DOENÇA DE ALZHEIMER
}

\section{PROJECT REQUIREMENTS FOR INTERIOR DESIGN AIMED TO ELDERLY WITH ALZHEIMER DISEASE}

\author{
Raquel Martinelli ${ }^{1}$, M.Sc. \\ Juliana Joenck Colle ${ }^{2}$, Grad.. \\ (1) Universidade Federal de Santa Catarina \\ e-mail: buono.disegno@gmail.com \\ (2) Universidade Federal de Santa Catarina \\ e-mail:juucolle@gmail.com
}

Palavras-chave: Ergonomia, Doença de Alzheimer, Design de Ambientes

É quase uma característica mundial que a família assuma a responsabilidade de zelar pelo idoso. Considerando a exigência de cuidados e atenção integral ao idoso com Doença de Alzheimer (D.A), tem-se observado que além da atenção psicológica, o ambiente construído também necessita de alterações pontuais. O presente estudo, parte da primeira etapa do trabalho de conclusão de curso, tem por objetivo identificar as principais necessidades ambientais específicas do idoso com D.A. e apontar soluções de caráter global, utilizando para tanto a metodologia Design Thinking. O estudo foi dirigido ao ambiente de banheiro devido ao alto índice de acidentes domésticos registrado neste local.

Key-words: Ergonomy, Alzheimer's Disease, Interior Design

It is almost a worldwide feature that the family assumes the responsibility of caring for the elderly. Considering the requirement of care and integral attention for the elderly with Alzheimer's Disease (A.D), it has been observed that in addition to psychological attention, the built environment also requires specific changes. The present study, it's part of the first stage of the course completion work, where the objective is to identify the main specific environmental needs of the elderly with A.D and to point out solutions of a global nature, using the methodology of Design Thinking. The study was directed for the bathroom environment due to the high rate of domestic accidents registered at this location.

\section{Introdução}

O presente trabalho é resultado da primeira etapa da elaboração do TCC denominado: "Diretrizes para design de interiores voltado a idosos com doença de Alzheimer: Projeto de banheiro residencial" cujo objetivo final é a realização de um projeto piloto para banheiro voltado ao idoso portador da doença de Alzheimer (D.A.). 


\section{$16^{\circ}$ \\ ERGODESIGN USIHC CINAHPA}

O material apresentado aqui refere-se a etapa de imersão, considerando a metodologia projetual do Design Thinking adotada e contempla, nesta etapa, os requisitos gerais de projeto para ambientes voltados ao idoso com Doença de Alzheimer. Nas etapas futuras esses requisitos serão canalizados especificamente para o projeto piloto de um banheiro voltado ao idoso com D.A.

\section{Contextualização}

Em 1997, as estatísticas da Organização das Nações Unidas (ONU) previam que somente em 2025 a população mundial chegaria em 802 milhões de idosos (TERCEIRA IDADE, 1999). Porém dados divulgados em 2015 pela mesma organização mostram que 901 milhões de pessoas possuem 60 anos ou mais, ou seja, $12,3 \%$ da população mundial são idosos (SORDI, 2015). Numa previsão para 2050, a Organização Mundial da Saúde (OMS) estima que a população mundial de idosos dobre, e no Brasil essa mesma população alcance aproximadamente $30 \%$ de brasileiros idosos (DIÁRIO CATARINENSE, 2016).

Apesar de todos os progressos da ciência, faz, infelizmente a velhice muitas vezes é acompanhada de senilidade. Como causa primária da demência senil temos a doença de Alzheimer, que causa a deterioração e redução das habilidades do ser humano (MINAYO et al., 2002). Segundo o Instituto Alzheimer Brasil (IAB), no Brasil presume-se haver 1 milhão e 200 mil pessoas portadoras da doença de Alzheimer, surgindo cerca de 100 mil novos casos por ano.

\subsection{Problemática}

Como o design pode oferecer produtos e ambientes que auxiliem o idoso com a doença de Alzheimer em tarefas básicas no ambiente residencial, dando mais autonomia e segurança para o mesmo, e contribuindo com os familiares e/ou seus cuidadores?

\subsection{Objetivos}

\subsubsection{Objetivo Geral}

$16^{\circ}$ Ergodesign - Congresso Internacional de Ergonomia e Usabilidade de Interfaces Humano Tecnológica: Produto, Informações Ambientes Construídos e Transporte

$16^{\circ}$ USIHC - Congresso Internacional de Ergonomia e Usabilidade de Interfaces Humano Computador

CINAHPA | 2017 - Congresso Internacional de Ambientes Hipermídia para Aprendizagem.

Elaborar lista de requisitos para o desenvolvimento de projeto piloto para banheiro doméstico voltado ao idoso com de D.A.

Na segunda fase do Trabalho de Conclusão de Curso, essa lista tornará possível a elaboração de um projeto piloto de banheiro voltado ao idoso com D.A.

\subsubsection{Objetivos Específicos}

a) conhecer as patologias da terceira idade, bem como a principal demência de causa primária que é a Doença de Alzheimer;

b) entrevistar e observar familiares e cuidadores dos idosos com doença de Alzheimer (D.A.) para verificar os principais problemas e necessidades destes idosos em relação a suas residências;

c) analisar pontos positivos e negativos de manuais e entidades voltadas para portadores de D.A.;

d) gerar lista de requisitos para projeto de ambientes voltados ao idoso com Doença de Alzheimer;

\subsection{Justificativa}

Com o envelhecimento da população brasileira e mundial, acompanhado do aumento dos casos da Doença de Alzheimer (DA), cresce também a demanda por instituições, equipamentos, profissionais especializados, pesquisas e diversos outros serviços de atendimento a esses idosos.

É quase uma característica mundial que a família assuma a responsabilidade de cuidar do idoso - ao invés de colocá-lo em alguma instituição. Essa característica do cuidado pelo sistema de suporte informal, se dá por questões culturais, financeiras e emocionais (MINAYO et al., 2002).

É visível que a grande maioria dos familiares e cuidadores dos idosos não possui suporte para lidar com todas as mudanças trazidas pela doença tanto em termos psicológicos e, principalmente, no que se refere ao ambiente físico. Essa carência é evidente diante dos dados revelados pelo Sistema Único de Saúde (SUS), o qual constatou que 75\%
Realização:

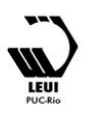




\section{$16^{\circ}$ \\ ERGODESIGN USIHC CINAHPA}

das lesões sofridas por pessoas com mais de 60 anos são causadas por acidentes domésticos e o trajeto quarto-banheiro é o que oferece maior risco, principalmente durante a noite (MACEDO, 2013).

\section{Metodologia}

Foi desenvolvida uma pesquisa que mostra o panorama do envelhecimento da população e as condições físicas e psicológicas que acompanham essa etapa da vida, considerando mais especificamente os sintomas ocasionados pela Doença de Alzheimer. Para tanto foram pesquisadas as características da doença, as consequências sobre a saúde física e mental do idoso e de que maneiras este passa a interagir com o ambiente construído.

Para elaborar as diretrizes projetuais de um ambiente voltado ao idoso com Doença de Alzheimer (D.A.), foi utilizada a metodologia projetual do Design Thinking, pretendendo como resultado final chegar ao detalhamento do projeto piloto de um banheiro.

O método foi selecionado pois, segundo Silva et al. (2012, p.12): "é uma abordagem focada no ser humano que vê na multidisciplinaridade, e tangibilização de pensamentos e processos, caminhos que levam a soluções inovadoras para negócios".

Silva et al. (2012) descreve o Design Thinking como um processo dividido em três etapas: Imersão, Ideação e Implementação (fig.01). A divisão da metodologia em três fases é uma forma de organizar as ideias durante a execução do projeto, norteando o projetista durante todo o processo, ressaltando que as fases podem ser moldadas de acordo com a natureza do projeto. $16^{\circ}$ Ergodesign - Congresso Internacional de Ergonomia e Usabilidade de Interfaces Humano Tecnológica: Produto, Informações Ambientes Construídos e Transporte

$16^{\circ}$ USIHC - Congresso Internacional de Ergonomia e Usabilidade de Interfaces Humano Computador

CINAHPA | 2017 - Congresso Internacional de Ambientes Hipermídia para Aprendizagem.

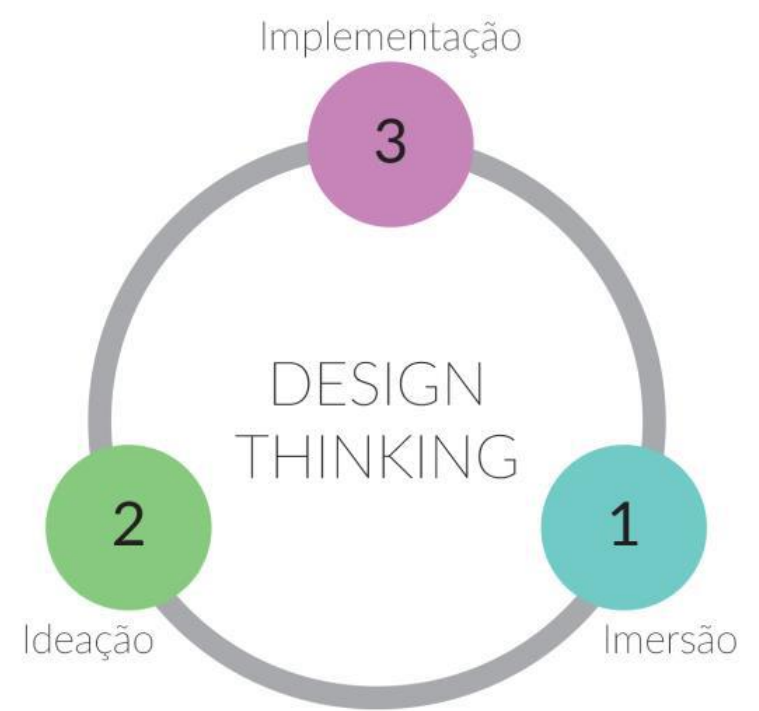

Figura 01: Metodologia Design Thinking. Fonte: os autores

Para cada etapa da metodologia adotada, serão utilizadas ferramentas de projeto como entrevistas e observação participante na pesquisa de campo, análise sincrônica de similares, painel semântico para a definição do público-alvo, mapas conceituais, entre outras que serão descritas ao longo do projeto.

Este trabalho trata exclusivamente da etapa de imersão, a qual terá como resultado a lista de requisitos que dará origem às etapas futuras de ideação e implementação, culminando com o projeto piloto para sanitário voltado ao idoso com D.A.

\subsection{Fase de Imersão}

A fase de Imersão é fundamental em um projeto, pois é nesta fase que se toma conhecimento de todos os aspectos da problemática estudada além de ser a etapa de definição do problema do projeto. A fase de imersão foi composta pelas seguintes análises:

- Pesquisa bibliográfica

- Campo de investigação: entrevista em instituição asilar privada para idosos e observação de encontro entre familiares de idosos com Alzheimer

\subsubsection{Pesquisa Bibliográfica}

Para este trabalho se fez necessário tanto a
Realização:

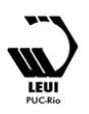




\section{$16^{\circ}$ \\ ERGODESIGN USIHC CINAHPA}

utilização de livros e artigos acadêmicos da área médica, principalmente da gerontologia e da psicologia, quanto de materiais sobre Arquitetura e Ergonomia, para analisar e auxiliar a elaborar um projeto adequado como solução final.

Os tópicos abordados pela pesquisa bibliográfica foram os seguintes:

- A Doença de Alzheimer, causas, fases, sintomas e tratamentos farmacológicos e não farmacológicos; - Familiares do idoso com Doença de Alzheimer; - Design e fatores ambientais para o portador de Doença de Alzheimer: Ergonomia, Conforto acústico e lumínico, Antropometria, NBR 9050, Acessibilidade e Automação residencial;

\subsubsection{Coleta de dados}

Nessa etapa foram revisados artigos sobre o tema, entrevista, observação participante, análise sincrônica de manuais voltados ao cuidado do paciente com D.A. e de instituições para idosos. A entrevista foi realizada com o proprietário de uma casa de repouso, localizada em FlorianópolisSC. A entrevista foi do tipo não-estruturada, porém com roteiro pré-estabelecido. A observação dos internos não foi permitida.

Também foi realizada observação participante em reunião do grupo de apoio à família do portador de Alzheimer, projeto desenvolvido no Hospital Universitário da Universidade Federal de Santa Catarina.

\section{Análise dos dados}

A busca de artigos resultou em vários trabalhos voltados ao idoso e suas necessidades ergonômicas e ambientais, mas sem especificação ao idoso com Doença de Alzheimer.

A entrevista feita na casa de repouso forneceu dados importantes sobre o comportamento cotidiano do idoso com D.A., como por exemplo a falta de significado de palavras e objetos. Foi significativa a referência a "síndrome do pôr-dosol”, desorientação que acomete os pacientes ao anoitecer, provavelmente motivada pela redução na iluminação.

A observação participativa ao grupo de apoio forneceu aspectos importantes da convivência do idoso em ambiente doméstico, como as $16^{\circ}$ Ergodesign - Congresso Internacional de Ergonomia e Usabilidade de Interfaces Humano Tecnológica: Produto, Informações Ambientes Construídos e Transporte

$16^{\circ}$ USIHC - Congresso Internacional de Ergonomia e Usabilidade de Interfaces Humano Computador

CINAHPA | 2017 - Congresso Internacional de Ambientes Hipermídia para Aprendizagem.

dificuldades no uso do banheiro, a necessidade de acompanhamento e o sono conturbado. A busca por manuais de orientação relativos à Doença de Alzheimer revelou maior preocupação em esclarecer a doença e seus sintomas, com poucas referências ao ambiente. A análise de projetos de instituições para idosos apresenta duas instituições que, de modo geral, garantem um ambiente adaptado seguindo normas técnicas e medidas de segurança, mas a um custo inviável para a maioria.

\section{Definição do público alvo}

Segundo Pazmino (2015), a definição correta do público-alvo é importante para um bom desenvolvimento do projeto, pois é esse grupo de usuários que dará as diretrizes e características para o projeto final.

O público-alvo deste projeto são idosos com idade acima de 65 anos diagnosticados com doença de Alzheimer (DA) nas fases leve e moderada da doença e que, portanto, ainda possuem certa autonomia para realizar algumas atividades ao ar livre (caminhadas, passeios e compras), assim como para realizar tarefas básicas dentro da residência (higienização, vestuário, alimentação), em alguns casos (devido à instabilidade da doença) necessitando do auxílio de um acompanhante.

\section{Requisitos de projeto}

Os requisitos de projeto surgem após a análise dos dados e a definição clara do público-alvo. Neste trabalho os requisitos foram norteados pela elaboração de mapa conceitual, um painel de conceito, um painel de referências projetuais e, principalmente, uma lista de requisitos elaborada com base em toda a pesquisa realizada.

\subsection{Mapa conceitual}

O Design Thinking sugere a utilização de mapa conceitual como ferramenta para facilitar a compreensão de informações complexas nos seus diferentes níveis, além de servir para comunicar a síntese da pesquisa (SILVA et al, 2012). Pazmino (2015) diz que a ferramenta representa graficamente o pensamento criativo, reunindo em um só lugar grande quantidade de dados. 


\section{$16^{\circ}$ \\ ERGODESIGN USIHC CINAHPA}

O objetivo da ferramenta é, enfim, definir os requisitos gerais que irão nortear o projeto.

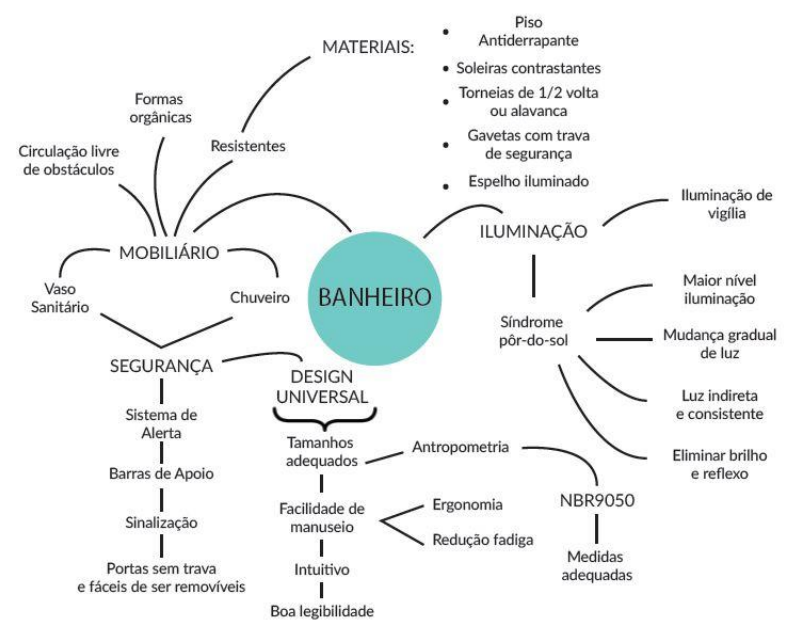

Figura 02: Mapa conceitual para projeto de ambientes com foco no banheiro.

Fonte: os autores

\subsection{Requisitos gerais de projeto}

A partir do desenvolvimento do mapa conceitual foi possível enumerar os principais requisitos que irão nortear o projeto:

- Usabilidade do ambiente: A usabilidade é uma característica que engloba vários fatores, como a baixa taxa de erros, facilidade de aprendizagem, desempenho rápido e está diretamente ligada com o intuitivo e a simplicidade (SILVA FILHO, 2008). Pessoas com Alzheimer necessitam de um ambiente que seja simples e minimizem seus erros ao máximo, já que a perda do significado dos objetos e das coisas é muito recorrente no ambiente.

- Conforto: O conforto se mostrou uma das características mais importantes no ambiente para o idoso. Podemos considerar o conforto térmico, acústico e lumínico. O conforto térmico determina a temperatura adequada nos ambientes de convivência do idoso, devendo ser observadas as questões subjetivas de cada um. O conforto lumínico cuida de manter a iluminação adequada para a manutenção das atividades cotidianas, sem excessos que provoquem ofuscamento e desorientação. É importante trazer a questão da 'síndrome do pôr-do-sol' que exigirá iluminação $16^{\circ}$ Ergodesign - Congresso Internacional de Ergonomia e Usabilidade de Interfaces Humano Tecnológica: Produto, Informações Ambientes Construídos e Transporte

$16^{\circ}$ USIHC - Congresso Internacional de Ergonomia e Usabilidade de Interfaces Humano Computador

CINAHPA | 2017 - Congresso Internacional de Ambientes Hipermídia para Aprendizagem.

interna constante no intervalo dia/noite. Considerando o aspecto de os idosos levantarem várias vezes no meio da noite (relatado na observação participativa) faz-se necessário prover, ao menos as circulações, de luzes balizadoras. $\mathrm{O}$ conforto acústico se dará à medida em que os ambientes forem guarnecidos por revestimentos absorventes das ondas sonoras. Isso reduzirá a reverberação, garantindo tranquilidade e audição mais eficaz.

- Segurança: A segurança está intimamente ligada à movimentação do idoso. A maioria dos relatos de queda se dá quando o idoso se movimenta sozinho e, principalmente à noite. Aliado a isso salienta-se a necessidade de salientar degraus, retirar tapetes e moveis leves e com rodízios (se usados como apoio fatalmente levariam à queda) além de utilizar revestimento de piso antiderrapantes.

- Resistência: Uso de materiais e, principalmente, mobiliários com alta resistência mecânica, pois servem como apoio nos momentos de sentar/levantar.

- Formas orgânicas: Estão diretamente ligadas à segurança do idoso, lembrando que a perda de significado dos objetos para o portador de D.A. pode fazer com se machuque facilmente com qualquer objeto.

-Aspectos dimensionais: Dado que muitos dos idosos com D.A. necessitam de ajuda para algumas atividades cotidianas, entende-se que os espaços devam ser dimensionados para o usuário e seu acompanhante, prevendo espaço necessário para os movimentos de ambos.

De forma geral, serão trabalhados os conceitos do Desenho Universal, que possui sete princípios descritos por Cambiaghi (2012) como:

1. Uso equitativo: design destinado a pessoas com diferentes habilidades, evitando segregar ou estigmatizar qualquer usuário.

2. Flexibilidade no uso (adaptável): acessível e utilizado por destros e canhotos; oferecer adaptabilidade ao ritmo do usuário. 


\section{$16^{\circ}$ \\ ERGODESIGN USIHC CINAHPA}

$16^{\circ}$ Ergodesign - Congresso Internacional de Ergonomia e Usabilidade de Interfaces Humano Tecnológica: Produto, Informações Ambientes Construídos e Transporte

$16^{\circ}$ USIHC - Congresso Internacional de Ergonomia e Usabilidade de Interfaces Humano Computador

CINAHPA | 2017 - Congresso Internacional de Ambientes Hipermídia para Aprendizagem.
3. Uso simples e intuitivo: compreensão do design deve ser independente da experiência do usuário, conhecimento, competência linguística ou concentração; deve eliminar complexidades desnecessárias.

4. Informação perceptível: capaz de comunicar e informar, independentemente da habilidade e capacidade sensorial do usuário ou ambiente em que se encontra.

5. Tolerância ao erro (seguro): minimizar os riscos e consequências de ações acidentais.

6. Mínimo esforço físico (menor fadiga): utilização de formas eficientes e confortáveis, com o mínimo de esforço, minimizando ações repetitivas.

7. Dimensionamento de espaços para acesso e uso (uso abrangente): oferecer espaços e dimensões apropriadas ao uso, independentemente do tamanho ou da mobilidade do usuário.

\section{Conclusão}

Dentro da metodologia do Design Thinking a etapa de imersão foi fundamental para conhecer o tanto o sujeito do projeto (idoso portador de D.A.), quanto as necessidades específicas da doença. As entrevistas e a observação participativa enriqueceram o conteúdo por meio das vivências familiares e, ao unir todas essas informações obteve-se uma lista de requisitos com referência às necessidades do idoso com D.A.

De posse de todos esses dados o trabalho evoluirá para as fases de ideação e implementação, onde resultará em um projeto piloto contendo todas as recomendações necessárias para um banheiro adaptado ao idoso com D.A. O fato das recomendações serem apresentadas no formato de projeto se deve à necessidade de se fazer compreender por todos que necessitem executar modificações nos ambientes já construídos de modo a tornarem a convivência dos idosos mais segura e confortável.

\section{BIBLIOGRAFIA}

CAMBIAGHI, S. Desenho Universal: Métodos e técnicas para arquitetos e urbanistas. 3. ed. São Paulo: Senac São Paulo, 2012. 283 p.

DIÁRIO CATARINENSE: População idosa do país vai triplicar em $\mathbf{4 0}$ anos. Florianópolis, 30 ago. 2016.

MACEDO, T. Acidentes domésticos somam 75\% das lesões sofridas por idosos. JM Online, Uberaba, 02 de outubro de 2013. Seção Saúde. Disponível em <http://www.jmonline.com.br/novo/?noticias,7,SA DE,86145>. Acesso em: 24 de agosto de 2016.

MINAYO, M. C. de S. et al (Org.). Antropologia, Saúde e Envelhecimento. Rio de Janeiro: Fiocruz, 2002. $212 \mathrm{p}$.

PAZMINO, A. V. Como se cria: 40 métodos para design de produtos. São Paulo: Blucher, 2015. $279 \mathrm{p}$.

SILVA FILHO, A. M. da. Simplicidade e imaginação do design de produtos: fatores essenciais à usabilidade. 2008. Disponível em: <http://www.espacoacademico.com.br/091/91 amsf.htm>. Acesso em: 10 nov. 2016.

SILVA, M. J. V. e et al. Design Thinking:

Inovação em Negócios. Rio de Janeiro: Mjv Press, 2012. $162 \mathrm{p}$.

SORDI, J. Número de idosos quase triplicará no Brasil até 2050, afirma OMS. 2015. Disponível em: <http://zh. clicrbs.com.br/rs/vida-eestilo/vida/noticia/2015/09/numero-de-idososquase-triplicara-no-brasil-ate-2050-afirma-oms4859566.html\# >. Acesso em: 18 de Agosto de 2016.

TERCEIRA IDADE: a nova onda. Brasília: O Correio da Unesco, n. 20, mar. 1999. 